\title{
AUTOCONSCIÊNCIA PURA, IDENTIDADE E EXISTÊNCIA EM KANT
}

\author{
Clélia A parecida MARTINS ${ }^{1}$
}

- RESUM 0: Este artigo estabelece a relação entre apercepção transcendental e identidade, existência e percepção, e procura com isso mostrar que, embora esteja na base da estrutura cognitiva humana, a autoconsciência não elabora conhecimento.

- PALAVRAS-CHAVE: Autoconsciência pura; estrutura cognitiva; identidade; percepção.

Um ponto fundamental predominante na atual interpretação sobre a teoria da autoconsciência de Kant, defendido por Sturma, ${ }^{2}$ Frank, ${ }^{3}$

1 Departamento de Administração e Supervisão Escolar - Faculdade de Filosofia e Ciências - UNESP - 17525-900 - Marília - SP - Brasil.

2 "O sujeito do pensar sabe só de si, porque ele é dado como objeto da experiência no espaço e no tempo, o que não só é a suposição para o reconhecimento do sujeito racional por outros, mas também para a sua própria autoconsciência e sua auto-experiência. Esta suposição diz respeito diretamente ao núcleo cognitivo da autoconsciência, pois na autoconsciência o sujeito do pensar tem uma consciência de si como existindo no mundo e, ao mesmo tempo, de ser diferente de todos os seus objetos e casos, porque se precisa também compreender a autoconsciência como uma regulação cognitiva" (Sturma, 1985, p.104).

Sturma afirma também que "Nisso a tese do $\$ 25$ da TD B tem: eu na síntese transcendental do múltiplo das representações sou consciente de mim; que eu sou o que é um pensar não um intuir [B 157 e XXII: 48: '0 homem enquanto é consciente de seu eu (ele seu objeto), pensa'], um significado extraído para a relação entre a crítica do conhecimento e a teoria da autoconsciência." (1985, p. 85).

3 "O princípio desta dedução, o próprio eu, somente foi importante para ele [Kant] por causa da - na verdade indispensável - natureza de princípio, em outras palavras: por causa das conseqüências que fluem dele para uma explicação do fundamento da objetividade" (1993, p.418). 
Henrich, ${ }^{4}$ dentre outros, é de que a autoconsciência é, em si, o núcleo do conhecimento, em cuja origem está a identidade do eu. Conforme esta interpretação, o "eu" é o fundamento da objetividade e, por conseguinte, esses autores consideram que 0 estudo deste por parte de Kant está voltado para essa objetividade. Seria isso correto, se o fim da obra de Kant fosse a análise de um eu empírico e cognitivo, mas, ao contrário, este eu e a própria teoria do conhecimento parecem ser dois tópicos muito importantes na filosofia transcendental, porém, ela não se esgota em um esclarecimento destes tópicos, o que, portanto, não permite deduzir que os estudos da autoconsciência relativos ao "eu" tenham sido realizados apenas para fundamentá-lo.

A pesar de haver autoconhecimento apenas porque existe autoconsciência ${ }^{5}$ e de que esta deva ser considerada "uma faculdade sublime" $(X X, 270),{ }^{6}$ será demonstrado no decorrer deste texto que Kant estudou a estrutura analítica da coutoconciência, isto é, abordou-a como apercepção pura, o que inviabiliza conhecê-la como um núcleo cognitivo próprio - pois que nela o saber, que o sujeito adquire de si, consiste em uma percepção e não em um ato de conhecer. A autoconsciência, em si mesma, embora esteja na base da estrutura cognitiva humana não elabora conhecimento - nessa estrutura a produtora de conhecimento é a autoconsciência empírica. Não há possibilidade de "conceituações" na autoconsciência: no estrito sentido da atividade cognitiva, como produtora de conceitos, este tipo de interpretação não cabe à autoconsciência.

4 Henrich (1989, p.42-92) entende que na origem da objetividade das coisas singulares, que é uma função da verdade dos juízos, está a identidade do eu. Como será exposto neste texto, em Kant a identidade só está relacionada à autoconsciência pura e não à consciência empírica, produtora de objetividade, assim, há um engano da parte de Henrich.

5 "Para um tal autoconhecimento precisarão ser supostas a unidade e a identidade da autoconsciência, porque este autoconhecimento tem por condição necessária a estrutura da referência das simples representações de 'eu penso' às representações isoladas e possivelmente dadas" (Becker, 1994, p.250).

6 As citações das obras de Kant têm como base a edição da Academia (Kants Gesammelte Schriften, organizado pela Preussischen und Deutschen A kademie der Wissenschaften, Berlim, 1902 ss.) apenas algumas citações da Anthropologie se fazem com base na edição da Wilhelm Weischedel Werksausgabe e, neste caso, o número do volume (XII) é precedido da sigla W. O volume da obra citada está em números romanos e as páginas são indicadas em números arábicos. Doravante, as páginas da Crítica da razão pura precedidas da letra $\mathrm{A}$ correspondem à edição de 1781, e da letra $\mathrm{B}$, à edição de 1787. Os textos de Kant que se apresentam indicados de forma abreviada são: Anthropologie in pragmatischer Hinsicht (Anthropologie), Kritik der praktischen Vernunft (KpV), Kritik der reinen Vernunft (KrV), Die M etaphysik der Sitten (MS), Prolegomena zu einer jeden künftigen Metaphysik (Prolegomena). 
Ao se abordar a apercepção transcendental e a identidade do sujeito, temos de considerar que Kant indica um primeiro ato como a origem da consciência. No ramo da filosofia teórica, ele concede a maior importância à autoconsciência, que denominou também de "eu transcendental" ou "apercepção transcendental". ${ }^{7}$ Esta apercepção deve ser a "faculdade radical de todo nosso conhecimento" (A 114) e atuar como "o supremo ponto" no qual todo uso do entendimento deve se apoiar (B $134 \mathrm{n}$.).

0 "eu sou" como ato originário da nossa consciência é uma interpretação de Kant prevalecente no Opus Postumum, ${ }^{8}$ mas, na KrV, ao contrário, predominará a compreensão de que o "eu penso" é o primeiro ato de abstração da consciência: no ato "eu penso" o sujeito abstrai, isto é, ocorre abstração da aplicação das funções lógicas do pensar sobre o múltiplo (B 135 e 137). A interpretação do Opus Postumum corresponde com clareza à tese de Kant sobre a autoconsciência: o "eu sou" pode ser considerado a autoconsciência, pois é um ato lógico, ${ }^{9}$ que precisa valer como juízo analítico: " ${ }^{10}$ "Somente a consciência de meu eu (sum) a qual é lógica (cogito) não como um raciocínio (ergo sum) mas segundo a regra de identidade (sum cogitans) na qual o ato de representação, isto é, o pensar, é encontrado ainda sem síntese do múltiplo da intuição, mas contém o simples juízo analítico." (XXII, 83). Na KrV, este juízo analítico significa que, na simples autoconsciência, a representação do próprio sujeito é direta e nela existe a abstração de suas características (A 355). Como será visto, em muitas passagens da KrV , o "eu penso" é igualmente definido como ato lógico. Dessa perspectiva, o "eu sou" e o "eu penso" podem ser identificados como expressões da autoconsciência. Mas é preciso considerar que até mesmo na Dialética transcendental, precisamente no segundo paralogismo, Kant, ao

7 Enquanto a autoconsciência é um tema da filosofia antiga e medieval, a Kant coube a especificidade de compreendê-la como apercepção transcendental (Brandt, 1994, p.1).

8 XXII, por exemplo na p.115.

9 "A consciência lógica de meu próprio Eu (Sum) não contém definição, mas a consciência real da intuição (apperception)/Eu sou: é o ato lógico que antecede perante a toda representação do objeto, é um Verbum por meio do qual eu mesmo me coloco..." (XXII, 85).

10 A interpretação de Kant de juízo analítico é bastante clara já antes dos anos 70: "Todos os juízos analíticos ensinam, mas confusamente, o que é pensado nos conceitos: os sintéticos, o que deverá ser pensado unido ao conceito ... todos os juízos analíticos são racionais e vice-versa, todos os juízos sintéticos são empíricos e vice-versa ... In philosophia non dantur principia synthetica nisi a posteriori, i.e. impyrice, et principia analytica a pirori, h.e. propositiones elementares, utraque, materialia". (Refl. 3738; XVII, 278).

Segundo a reflexão 3767 (XVII, 288), os juízos analíticos referem-se à necessidade racional e os sintéticos, à necessidade empírica. 
expor a consciência como adquirida de um ato de abstração, partindo da unidade originária sintética da apercepção, não negará o "eu sou" como a proposição primeira de todo pensamento: "Do mesmo modo, a simplicidade de mim próprio (como alma) não é efetivamente deduzida da proposição eu penso, mas é primeira em todo o pensamento mesmo. A proposição eu sou simples deve considerar-se expressão imediata da apercepção ... Eu sou simples não significa, porém, senão que esta representação eu não contém em si a mínima multiplicidade e que é uma unidade absoluta embora puramente lógica" (A 354-5).

A autoconsciência como apercepção originária ou pura é a autoconsciência lógica ou transcendental. 0 "eu penso" é produzido por esta autoconsciência pura e espontânea; nesse sentido, ele pode ser considerado a representação "originária" de todas as demais ${ }^{11}$ - este "eu" não se produz, mas é um produto dessa autoconsciência. Essa espontaneidade ou apercepção pura não pode, por um um lado, ser identificada com a receptividade da sensibilidade porque nela o "eu penso" é apenas um ato, isto é, é 0 ato dela própria; por outro, ela também não pode ser confundida com a espontaneidade da razão prática, aplicada sobre as condições sensíveis e referida à causalidade da razão. ${ }^{12} \mathrm{~A}$ espontaneidade (pela qual o sujeito é consciente de si diretamente) é o conceito fundamental para entendermos a relação entre autoconsciência e consciência da espontaneidade nas funções lógicas do pensar: ${ }^{13}$ só a consciência da espontaneidade ou apercepção originária é que estabelece uma referência à identidade do sujeito. ${ }^{14}$

11 "Esta representação, porém, é um ato da espontaneidade, isto é, não pode se considerar pertencente à sensibilidade. Dou-lhe o nome de apercepção pura, para a distinguir da empírica ou ainda o de apercepção originária, porque é aquela autoconsciência que, ao produzir a representação eu penso, que tem de poder acompanhar todas as outras, e que é una e idêntica em toda a consciência, não pode ser acompanhada por nenhuma outra. Também chamo à unidade dessa representação a unidade transcendental da autoconsciência, para designar a possibilidade do conhecimento a priori a partir dela." (B 132).

12 O homem, por um lado, é "livremente fenômeno, mas por outro, do ponto de vista de certas faculdades, é também um objeto meramente inteligível, porque sua ação não pode de maneira nenhuma atribuir-se à receptividade da sensibilidade" (A 546-7/B 574-575). A causalidade da razão indica-se nos imperativos morais: "Que esta razão possua uma causalidade ou que, pelo menos, representemos nela uma causalidade, é o que claramente ressalta dos imperativos que impomos como regras, em toda a ordem prática, às faculdades ativas. 0 dever exprime uma espécie de necessidade e de ligação com fundamentos..." (A 547/,B 575, comparar com IV, 45).

13 “...esta identidade total da apercepção de um múltiplo na intuição contém uma síntese das representações e só é possível pela consciência desta síntese" (B 134). As funções lógicas do pensar tanto são uma expressão da simples espontaneidade como também por meio delas (quando aplicadas a um múltiplo da intuição sensível, isto é, quando categorias) o livre arbítrio é definido. Ver B 431-2.

14 "Não se estabelece, pois, essa referência [à identidade do sujeito, C. M.] só porque acompanho com a consciência toda a representação, mas porque acrescento uma representação a outra e tenho consciência da sua síntese" (B 133). 
0 conceito de identidade tem também sua importância nessa diferenciação: enquanto a consciência empírica não se refere a ele (B 133), a autoconsciência em geral é a própria identidade na medida em que é uma ligação originária (B 132-3), pela qual o múltiplo das representações fica ligado na consciência e só assim é possível "que eu a mim mesmo represente a identidade da consciência nestas representações ..." (B 133). Essa identidade é lógica, isto é, temos na autoconsciência a representação de nós como um "eu lógico", do qual, todavia nada mais sabemos ou podemos falar..$^{15} \mathrm{~A}$ consciência direta da própria espontaneidade na forma das funções lógicas do pensar é compreendida por Kant como um princípio ou juízo analítico: a simples unidade lógica da autoconsciência é uma unidade analítica. Assim, no §16 da Dedução transcendental, temos: "Este princípio da unidade necessária da apercepção é, na verdade, em si mesmo idêntico, portanto um princípio analítico..." (B 135). Este princípio analítico - a operação (Verrichtung) do entendimento que diz respeito a sua capacidade (Vermögen) de ligar a priori e submeter o múltiplo das representações à unidade da apercepção - é, conforme B 135, o princípio supremo de todo conhecimento humano.

Uma limitação da espontaneidade e a aplicação das funções lógicas do pensar não estão implicadas na compreensão que temos de nós como pura espontaneidade. Pois nessa compreensão, as funções lógicas referem-se apenas a algo indefinido, indeterminado. Em B 157, temos que, na unidade sintética originária da apercepção, a autoconsciência não está relacionada à intuição: "Ao contrário, tenho consciência de mim próprio na síntese transcendental do múltiplo das representações em geral, portanto, na unidade sintética originária da apercepção, não como apareço a mim próprio, mas tenho apenas consciência que sou. Esta representação é um pensamento e não uma intuição". A autoconsciência é obtida na espontaneidade das simples funções lógicas do pensar sem que seja necessário se pensar uma unidade sintética das representações, isso porque essa autoconsciência é apenas a consciência de uma espontaneidade e não remete a nenhum tipo de intuição que possa envolvê-la: "O pensar, considerado em si, é simplesmente a função lógica, por conseguinte, a simples espontaneidade da ligação do múltiplo de uma intuição apenas possível e não apresenta o sujeito da cons-

15 "O eu como sujeito do pensar (na lógica), o qual significa a pura apercepção (o simples eu reflexivo) e do qual nada mais [há, C. M.] para dizer, senão que é uma representação totalmente simples." (VII, 134, comparar com XVIII, 306 e XX, 33). 
ciência como fenômeno, porque não considera a espécie de intuição, isto é, se esta é sensível ou intelectual" ${ }^{16}$

Com isso, Kant entende que o conceito de autoconsciência permite ao sujeito tornar-se consciente de uma espontaneidade. Essa espontaneidade supõe um "eu-representação" vazio ou uma simples representação do "eu" que é a consciência transcendental, uma autoconsciência que unifica todas as demais consciências. ${ }^{17}$ Esse "eu" nos é desconhecido porque a autoconsciência é incondicionada; ${ }^{18}$ assim ele é uma representação sem conteúdo ${ }^{19}$ e sua obscuridade ${ }^{20}$ seu caráter imperscrutáve ${ }^{21}$ é o que Strawson adjetiva como seu significado não-denotativo, ${ }^{22}$ o qual designa a própria consciência em geral. ${ }^{23}$

$\mathrm{Na}$ A nthropologie, a apercepção pura ou transcendental foi indicada como uma consciência do "eu da reflexão" (VII, 141) e também como "o eu como sujeito do pensar" (VII, 134 n.). Na KrV, a representação deste "eu" é caracterizada como uma "representação simples e por si mesma totalmente vazia no conteúdo" (A 345-6, B 404). Como simples representação que não contém múltiplo, esta apercepção não tem conteúdo (A 381-2), mas tem fundamento e este está precisamente nas relações do

16 B 428-429. E continua: "...na consciência de mim mesmo, no simples pensamento, sou o próprio ser, mas deste ser ainda nada me é dado para o pensamento" (B 429).

17 "Não se deve deixar de considerar que a simples representação eu, em relação a todas as outras (cuja unidade coletiva torna possível), é a consciência transcendental" (A 118).

18 "Por isso a autoconsciência em geral é a representação daquilo que é a condição de toda a unidade, mas em si mesmo, é incondicionada" (A 401).

19 "....porque esta representação não tem conteúdo e, portanto, múltiplo algum, o que faz que pareça também representar, ou melhor dito, designar um objeto simples" (A 381-82).

20 Não pode haver, segundo Kant, pretensão em esclarecer o "eu": "...não temos nenhum conhecimento do sujeito em si que, na qualidade de substrato, esteja na base desse sujeito lógico, bem como de todos os pensamentos" (A 350, comparar com A 402).

21 Esse caráter imperscrutável parece determinar a própria oscilação com que Kant pensou esse eu Em A 341/B 399 ele é considerado um conceito ou um juízo; em A 382, na MS (IV 543 n.) e no Prolegomena é lhe negado um status conceitual: "Pois o eu é realmente sem conceito" (IV, 334). Também na reflexão 3921 prevalece um "eu" sem conceito, mas ele é apresentado como sensação: “Por isso, também não é estranho que nós não reconheçamos o sujeito perante todos os predicados, como simplesmente o eu que, sem embargo, não é conceito, mas uma intuição (sensação)" (XVII, 345-346). Já na reflexão 4425 o "eu" é apenas uma intuição: "O eu é uma representação obscura. Ela é uma intuição, a qual é invariável" (XVII, 465).

22 "... but it [l] is clear that Kant sees himself as giving a non-denotative account of ist significance; and it is also clear that he sees the rational psychologist as misconstruing the ' $I$ ', in its non-denotative significance, as denotative..." (Strawson, 1987, p. 207).

23 "So though the reational psychologist's 'I' has a non-designative or non-denotative role as signifying consciousness in general, it really does have a designative role to ... Only, in ist designative role it is nothing more than the thought of an object in general (B, p.429) and carries no know ledge whatever of the character or mode of existence of the subject in itself" (Strawson, 1987, p.208). 
"eu" com seus pensamentos, pois a pura apercepção é a consciência de um sujeito, sobre o qual é referido todo pensar como seu "sujeito comum" (A. 350), um sujeito que é "em todos os juízos sempre um e o mesmo" (VII, 141), o qual não é compreensível e nem existe independente deste pensar.

Por isso a relação do sujeito pensante com seus pensamentos é definida por Kant como uma "forma" (Form), na qual surgem os pensamentos em geral e por meio da qual este sujeito sabe que "pensa". Daí o "eu" da apercepção pura dizer respeito à simples forma da consciência (382) e ser um eu vazio: a sua relação com os pensamentos caracteriza o "formal da consciência" (VIII, 141): sua representação é sem representação dos pensamentos porque ela apenas caracteriza a forma na qual temos representações.

Quando Kant afirma que a pura apercepção atua como "condição transcendental" (A 341; B 399), ele simplesmente quer dizer que todo conhecimento está sob a suposição de que todas as representações possíveis de serem pensadas por nós poderão ser relacionadas a um "eu" idêntico, e que também é possível um saber a priori de que o pensar está sob tal condição (A 108 e 116) porque a ela é uma condição formal do pensar das representações, embora todas as representações do "eu" precisam ser dadas a ele, pois o "eu pensante" não as produz, apenas as liga (B 133). A apercepção por meio do entendimento da síntese produzida é "nada outra que a unidade da ação" (B 153), por isso, "eu posso ligar numa consciência um múltiplo de representações dadas" (B 133). Em B 154, a apercepção é definida como a "fonte de toda ligação" ("Quell aller Verbindung"). E porque a pura apercepção é uma condição formal do pensar, ela não pode ser equiparada com um autoconhecimento a priori do sujeito pensante nem com um autoconhecimento empírico do sujeito cognitivo, embora seja esta a compreensão de Guyer (1987, p.136 e 148) ao considerar um empirical knowledge of the self como alternativa à apercepção pura.

A pura apercepção não significa, portanto, o autoconhecimento de um sujeito pensante e tampouco o conhecimento de seus pensamentos empíricos e de seus estados mentais; pois ela apenas determina a forma na qual este sujeito tem conhecimentos sem ser, todavia, o saber de si que este sujeito tem e precisa ter. Portanto, como uma consciência do "eu da reflexão", o "eu penso" da apercepção transcendental não é o conhecimento de um ser que pensa, mas é uma consciência da forma na qual os pensamentos são pensados. Pode-se dizer então que o "eu" da apercepção transcendental tem uma característica negativa no que diz 
respeito aos conteúdos do pensar: ele é uma consciência de algo que não se refere a qualquer conteúdo mas tão-somente a um "Eu, como um ser pensante" (VII, 142). Aqui, uma incógnita parece inevitável: do que, precisamente, a apercepção é uma consciência se ela não está referida a uma pessoa que pensa nem a um conteúdo do pensar? Ela é a consciência da forma do pensar, é uma consciência em geral, e isso significa que 0 "eu" da apercepção pura é considerado em todo pensamento como 0 sujeito lógico do pensar (A 350) e, por isso, ele precisa e pode acompanhar ${ }^{24}$ todas as representações que temos: ele é o sujeito ao qual todos os pensamentos são inerentes (A 350 e 355$)^{25}$ e por ser consciente de si, sabe dessa relação dos pensamentos consigo: sem essa relação a ele, como sujeito dos pensamentos, não podem existir pensamentos, e isso caracteriza esta Form da apercepção transcendental como um "eu da reflexão".

Com isso, a pura apercepção é uma consciência do eu, isto é, a consciência de um sujeito de todos os pensamentos e também um saber de que todos os pensamentos são referidos a este sujeito - como o "sujeito" deles, os pensamentos são inerentes a ele. Ela é uma "apercepção pura que tudo abarca" ("allbefassende reine A pperception"), ou seja, ela é referente a todos os pensamentos dos quais podemos ser conscientes (A 123), e este é, conseqüentemente, o seu alcance. Kant sintetiza tal alcance com as seguintes palavras: "toda consciência empírica" tem "uma necessária referência à ... consciência de mim mesmo como apercepção originária" (A 117 n.).

A essa pura ou simples apercepção está ligado o sentido de substancialidade ${ }^{26}$ do "eu" exposto tanto na A nthropologie como também na teoria da apercepção transcendental da KrV de 1781. Os pensamentos e o pensar são, por conseguinte, tal como está no paralogismo a, efeitos ou fenômenos da substância pensante (A 352), e o máximo que nossa compreensão pode alcançar é este "eu" como tal substância pensante (A 356).

24 No §16 da Dedução B Kant diz que uma representação é algo "para mim". Isso significa que ela poderá ser pensada por mim e a condição para isso é que o "eu penso" precisa poder acompanhála, pois o "ato da espontaneidade" ("A ktus der Spontaneität") não a produz, apenas a acompanha (B 132).

25 A tese da "consciência acompanhante" (begleitende Bewubtsein) não é algo novo e originário do pensamento de Kant. Como mostra Brandt (1983, XXVIII-XXIX), ela já existia em antigos tratados de filosofia e na filosofia do período de Kant ela está em um escrito de 1728 de autor anônimo inglês (Brandt, 1984, p.7).

260 eu expressa "não só a substância, mas também o substancial mesmo. 0 que ainda é mais, 0 conceito que nós temos em geral de todas as substâncias, nós plagiamos deste eu" (XXVIII, 226; comparar com Refl. 5404, XVIII, 174). 
0 "eu" da apercepção transcendental não existe independente dos seus pensamentos, por isso estes pensamentos são referidos sempre a um único e mesmo "eu". ${ }^{27} \mathrm{~A}$ apercepção é uma consciência de um sujeito caracterizado apenas por seus próprios pensamentos, daí ela ser um saber dos pensamentos definidos e pensados pelo sujeito. Assim, ela é a consciência de um eu único e um saber de que todos os pensamentos deste "eu" estão referidos a um único e idêntico sujeito. E porque a pura apercepção é esta consciência do "eu" como sujeito idêntico em todos os pensamentos, Kant entende que ela possui uma "unidade numérica" (A 107). 0 fato de todos os pensamentos (com os quais o "eu" é consciente de si) serem pensamentos de um mesmo "eu" caracteriza esta "unidade numérica" da apercepção. Essa unidade pode ser interpretada como um princípio independente da intuição sensível (B 137) porque ela é o pressuposto da unidade analítica da apercepção ${ }^{28}$ e fundamenta, conseqüentemente, a consciência empírica (o sujeito consciente desta "unidade" é o sujeito empírico e não o sujeito lógico, pois Kant nada diz sobre a consciência deste). Em outras palavras: a unidade da consciência é uma condição para que exista tanto a autoconsciência empírica como também o conhecimento empírico em geral.

A penas em razão dessa unidade nos é possível pensar o múltiplo em uma representação (A 353-4). Essa unidade, contudo, é subjetiva: ${ }^{29}$ "0 princípio formal da apercepção: eu penso" é também uma "simples condição subjetiva" (A 354) de um conhecimento geral. O "eu penso" só pode ocorrer se houver unidade absoluta do sujeito que pensa: a unidade do pensamento está ligada, sob determinadas condições, com a unidade absoluta do sujeito. ${ }^{30}$

27 "Portanto, todo o múltiplo da intuição possui uma relação necessária ao eu penso, no mesmo sujeito em que esse múltiplo será encontrado" (B 132).

28 "Só porque posso ligar numa consciência um múltiplo de representações dadas, posso obter por mim próprio a representação da identidade da consciência nestas representações; isto é, a unidade analítica da apercepção só é possível sob o pressuposto de qualquer unidade sintética." (B 133). E ainda: “... assim, a unidade sintética da apercepção é o ponto mais elevado a que se tem de suspender todo o uso do entendimento, toda a própria lógica e, de acordo com esta, a filosofia transcendental..." (B 134 n.).

29 Neste ponto, Kant entende que a psicologia racional erra ao considerar esta unidade absoluta como objetiva, interpretando a condição subjetiva do pensar humano como condição objetiva de todo ser pensante. Ver A 354 e $\S 12$, § 15 e $\S 16$.

30 Porém, esta unidade absoluta não é conclusiva da unidade do pensamento, pois surge apenas quando existe autoconsciência da parte do sujeito: "Pois, embora o todo do pensamento possa ser dividido e repartido por muitos sujeitos, não pode, contudo, o eu subjetivo ser dividido e distribuído, e esse eu nós o pressupomos, contudo, em todo o pensamento" (A 354). 
A pura apercepção define a forma pela qual os pensamentos e as representações poderão ser pensados. Com base nessa forma, tais representações e pensamentos pertencem a um único sujeito e isso é a consciência da identidade numérica do "eu", isto é, a consciência da unidade das representações de um sujeito apenas. Assim, a relação entre as próprias representações e um eu que as tem como um sujeito numericamente idêntico fundamenta a unidade destas representações, as quais só podem existir porque são todas representações e pensamentos de um "eu" idêntico.

0 saber de que as representações são representações de um e mesmo sujeito diz respeito à forma na qual este "eu", singular e idêntico consigo próprio, pode pensar as suas representações e refere-se, portanto, como fora expresso anteriormente, ao "formal da consciência" em todo conhecimento (VII, 141). Mas cabe notar aqui que esse conhecimento não é um conhecimento em si mesmo, pois a pura apercepção, como condição formal do pensar das representações, significa apenas que todas as representações, pensadas pelo "eu", são representações de um "eu idêntico". Para Kant, pensar é julgar, porque quando se julga se ligam as representações. Por exemplo, estar diante de um vaso de flores e ao mesmo tempo sentir um cheiro agradável vindo delas significa duas representações e para pensar sobre elas é necessário que se estabeleça uma conexão entre ambas que poderá ser articulada em um ou mais juízos (por exemplo: o vaso com flores produz um bom odor e deixa 0 ambiente mais bonito e ag radável), o que não quer dizer que seja preciso um pertencimento determinado (bestimmte Zusammengehörigkeit) entre as representações, como entendem Hinsch (1986, p.49) e M ohr (1991, p.123, 125 s.), mas apenas que elas, na forma do juízo, estejam ligadas umas com as outras. Quando o pensar de uma representação está em um juízo, ele está sob as condições formais da pura apercepção e as representações deste pensar são representações de um e mesmo sujeito, pois as representações só poderão ser ligadas a um juízo se elas estiverem sob tais condições: como condição formal do pensar das representações de um sujeito, a pura apercepção implica possibilitar a ligação das representações dadas a juízos mais ou menos complexos os quais, todavia, estão ausentes no sujeito pensante.

A unidade da apercepção, entendida como a consciência da identidade numérica do eu, fundamenta a consciência da unidade das representações nesse sentido, a apercepção transcendental é definida como forma de todo conhecimento. Embora essa consciência exista em um saber de que as representações são representações de um mesmo sujei- 
to, isso não significa que a consciência da unidade de todas as nossas representações é um saber de que um múltiplo qualquer ordenado é referido a um mesmo sujeito.

A pura apercepção, como consciência da identidade numérica do próprio eu, é a consciência de um sujeito idêntico que, como tal, atua sobre todos os seus pensamentos. Por isso, a possibilidade dessa consciência está ligada às representações em geral que o eu tem: Kant diz que as ligações da apercepção pura e da unidade das representações "podem estar juntas em uma autoconsciência geral" (B 132). Assim, só se podem ter representações se se pode ser consciente delas. Essa consciência das representações, que é a consciência empírica, supõe a apercepção transcendental e esta somente define a forma na qual as representações serão pensadas. As representações, tão logo possam ser pensadas pelo eu, pertencem à consciência de um eu idêntico, denominado também por Kant de "princípio transcendental da unidade de todo múltiplo de nossas representações" (A 341; B 399), pois a pura apercepção é, como forma do pensar, condição transcendental de todo conhecimento.

Com isso, fica esclarecido que a apercepção transcendental tanto contém uma unidade como também um saber, o qual, todavia, não é aceito para o fim de conhecimento de um objeto, mas diz respeito à "forma da representação em geral na medida em que deva ser denominada conhecimento..." (A 346; B 404). Como consciência (de que os pensamentos são pensamentos do próprio sujeito), ela é uma consciência da identidade do sujeito dêsses pensamentos e, por isso, uma consciência da unidade desses pensamentos que existe referida ao eu. Aqui pode-se entender a afirmação de Kant de que "toda consciência pertence a (minha própria) consciência": ${ }^{31}$ isso significa que a "apercepção pura que tudo abrange" (allbefassenden reinen A pperception - A 123) está ligada a sua unidade. Porém, isso não define o "eu" da apercepção transcendental em termos de conteúdo. Pois essa apercepção, por ser a consciência de um sujeito do pensar (o qual atua como um simples algo, e em razão disso não contém determinações, como por exemplo a de "extensão", para caracterizar a unidade da pura apercepção), fica definida como uma condição formal sob a qual está o pensar das representações, ou seja, fica definida como uma suposição a priori de todo conceito (A 107). Cremos que isto é o que Kant quer dizer quando define esta apercepção como "condição" e afirma que, como tal, ela não pode conter "uma ca-

31 A 117 n., comparar com A 113. 
pacidade para julgar sobre o passado" e ser aplicada "desta base" aos conceitos, o que Bennett (1966, p.117), lamentavelmente, defende.

A consciência do "eu" como ser pensante é a consciência de um e mesmo eu de todos os pensamentos; é a consciência de algo que "deverá ser representado necessariamente como numericamente idêntico" (A 107). Assim, só é possível ter pensamentos no modo em que tais pensamentos pertencem ao eu, daí a apercepção transcendental ser uma consciência de um eu, como sujeito de todos os pensamentos, idêntico numericamente. Para todos os pensamentos, só há um eu como sujeito do pensar, pois é 0 "eu" singular, como tema da pura apercepção, que define a forma do pensar, forma esta que temos no modo como o pensamento é pensado por um "eu" que só existe nisso, isto é, no fato de ele ter pensamentos: é um eu que nasce nos pensamentos, por isso ele não é compreensível independente deles. Ao definir a "forma" dos pensamentos que ele pensa, tal "eu" define o modo como tais pensamentos serão vistos. Trata-se, portanto, de um "eu", "que acompanha em todo o tempo as representações na minha consciência e realmente com perfeita identidade" (A 362-3).

\section{II}

Tendo já considerado a relação entre apercepção transcendental e a identidade do sujeito, é preciso considerar ainda que a autoconsciência pura contém a simples existência (B 422 n.): por um lado, só no "eu sou" está a possibilidade da existência; por outro, a única afirmação possível da autoconsciência é a da existência. ${ }^{32}$ Existe segurança só em relação à consciência da própria existência. A penas dessa existência é possível ter uma consciência infalível. Para Kant, eu estou para mim na autoconsciência diretamente consciente só de minha própria existência, encontrada por meio da percepção, a qual é determinação da apercepção (A 368). ${ }^{33}$ Certeza eu tenho e só é possível a respeito da própria existência; aqui Kant concorda com Descartes: "Por isso, Descartes tinha razão ao limitar toda a percepção no estrito sentido à proposição: eu sou (como um ser pensante)" (A 367-8).

32 “O pensamento: eu não sou, realmente não pode existir; pois [se, C. M.] eu não sou, então eu também não poderei estar consciente de que eu não sou ... negar na primeira pessoa 0 sujeito correspondente, ao que então extermina-se este [eu, C. M.], é uma contradição." (W XII, 465-6). “...que só aquilo que está em nós pode ser imediatamente percebido e que unicamente a minha própria existência pode ser objeto de uma simples percepção" (A 367). 
0 "eu sou" é pensado sem objeto exterior sobre o qual a existência possa ser deduzida e assim ele, sem objeto regular dos sentidos (A 367), não constitui um conhecimento precedente da mesma: "É certo que a representação eu sou, que exprime a consciência que pode acompanhar todo o pensamento, é o que imediatamente contém em si a existência de um sujeito, mas não é ainda nenhum conhecimento, portanto, não é também nenhum conhecimento empírico, ou seja, nenhuma experiência..." (B 277). Sem termos desta existência um conhecimento, também não podemos, por decorrência, tecer considerações sobre seu "local", como faz Becker ao pensar a consciência da existência localizada entre a simples consciência e a consciência empírica, ${ }^{34}$ local que, segundo ele, impossibilita que nela haja uma intuição sobre nós próprios. ${ }^{35}$ Se a interpretação de Becker fosse correta, então ela invalidaria a tese kantiana de que o conceito de existência é uma expressão direta da autoconsciência pura e que ele só é pensado nela, pois então o "eu existo" não seria idêntico ao "eu penso" (B 422 n.), um não estaria no outro, mas em partes separadas de nossa estrutura cognitiva (como é o caso da autoconsciência empírica e da simples autoconsciência). Compreender esse conceito de existência em Kant não se consegue por este caminho, ao contrário, o que se pode tentar verificar a este respeito é como tal conceito se coloca para ou perante a autoconsciência. Quando Kant o entende como idêntico ao "eu sou", ele nos dá um termo de comparação entre ambos, por isso é plausível concluir a semelhança entre eles, o que não significa entender que são um e mesmo conceito. $\mathrm{E}$, apesar dessa igualdade, a autoconsciência pensa a consciência da existência, como consciência das funções lógicas do pensar, tal como as percepções diretas que se têm do eu. Essa existência contida na autoconsciência, não se refere ao aspecto imediato (Unmittelbarkeit) da experiência exterior (B 276-7), nem

34 Becker, 1994, p.244; E ainda: "A definição de Kant da relação entre a autoconsciência da própria existência e a autoconsciência transcendental por um lado e por outro, com a consciência empírica é certamente assim, como ele a propõe em diferentes lugares na segunda edição, não livre de tensões. Enquanto encontram-se as definições expostas até aqui no capítulo dos paralogismos, antes de tudo o capítulo da dedução desperta a impressão de que Kant pensaria a consciência da própria existência como separada em alto grau da consciência empírica e indiretamente contida na autoconsciência transcendental" (p.245).

35 "Com isso, a consciência da própria existência é uma condição necessária, mas igualmente insuficiente, para a definição da própria existência; ela contém só a determinação da existência em si ... Porque a consciência da própria existência contém só a determinação mas não a definição da própria existência, está nela também consciente não o sujeito isolado, definido, mas apenas qualquer sujeito indefinido de representações empíricas indefinidas de modo geral. Disto resulta que, nesta consciência, falta uma intuição definida de si mesmo" (Becker, 1994, p.250). 
mediato da experiência interior, pois além de nenhuma experiência estar implícita nela, é-lhe suficiente que a representação "eu sou" seja um pensamento e não uma intuição. Como diz Kant no início do § 25 (B 157) e em A 639; B 667, para conhecer-me como objeto, seria necessário que me colocasse fora do pensamento como uma determinada intuição.

0 "eu sou", porque pensa a existência, na consciência, desvinculada das categorias ("existência não é aqui categoria" - B 423 n.) e possibilita um pensar a si próprio sem se referir à experiência, é apenas um juízo analítico, ${ }^{36}$ o que significa, em outras palavras, que a unidade lógica do sujeito é pensada como uma unidade analítica ${ }^{37}$ e que o "eu penso" da autoconsciência pura está para a existência como juízo analítico. ${ }^{38}$

Mas, se pensamos essa existência, de certa forma sabemos dela, embora este saber não possa ser entendido como próximo de conhecê-la, pois pensá-la significa entender que ela está na autoconsciência, embora 0 modo em que está, como está, seja indefinido. Como o saber sobre a existência e sobre a própria autoconsciência pura não ocorre como um conhecimento, então o que se tem de perscrutar é: "como" este saber é obtido sua origem ou os nossos mecanismos para obtê-lo; o que ele nos adianta sobre essa existência pensada no "eu penso" e, por conseguinte, sobre a própria autoconsciência em sua capacidade de pensar.

Sabemos que a existência é pensada desvinculada das categorias e, por isso, pode-se designá-la de existência neutra ou não-categorial (A 355; B 404; B 155-7), pois ela representa a existência não-empírica do sujeito. A esta existência pode-se entender que Kant faz referência ao falar de um "eu" como substância"39 (ao pensar a intuição não-sensível), ou seja, é pos-

36 A existência, quando articulada às categorias, referem-se os juízos sintéticos, os juízos de conhecimento: "Distingo a minha própria existência, como ser pensante, de outras coisas exteriores a mim (em que o meu corpo se inclui). Esta é igualmente uma proposição analítica ..." (B 409).

A existência não vinculada as categorias não pode expressar-se em juízos sintéticos, por estes estarem sempre referidos ao conhecimento da existência pensada categorial: "O primeiro ato sintético da consciência é 0 ato por meio do qual o sujeito se faz a si próprio por objeto da intuição, não lógico (analítico) segundo a regra da identidade, mas metafísico (sintético)" (XXII, 85).

37 No capítulo dos paralogismos, da segunda edição da KrV, Kant compreende a simples unidade lógica da autoconsciência como unidade analítica.

38 Embora já tenhamos esclarecido o que é juízo analítico para Kant, é oportuna aqui uma consideração sobre ele. Referindo-se a A 598-9 e B 626-7 (“'Existenz (Sein) kein reales Prädikat' sei"), Frank esclarece o que é um juízo analítico: “Com os juízos de exitência nada é julgado sobre o modo do ser (qualitas, realitas, quiditas): ser é sem característica neste sentido. Eu digo 'eu existo como inteligência', então a inteligência é um predicado real (pertencente a qualidade do cogito), e o juízo mesmo é 'analítico' (Kant diz também 'diretamente', 'tautológico' [A 354-5/XXIII, 11])" (1993, p.423). "...o conceito de uma substância, isto é, de algo que pode existir como sujeito, mas nunca como simples predicado, pois não sei se pode haver uma coisa que corresponda a esta determinação do pensamento, se uma intuição empírica não me der o caso para a aplicação" (B 149, comparar com B 419). 
sível conectá-la com a concepção da alma como substância, quando este conceito indica "uma substância na idéia, mas não na realidade" (A 351). ${ }^{40}$

0 eu como "substância" é definido como puro funcionalmente, ${ }^{41} \mathrm{e}$ com isso não serve para o autoconhecimento da alma - segundo o capítulo dos paralogismos a "substância" é um conceito epistemologicamente neutro referido apenas à autoconsciência pura. Tal como Aristóteles (Kategorien 2a-b) indicou - a substância é a suposição de toda "predicação" (Prädikation), mas não pode, ela própria, predicar -, Kant defende que só se pode falar da "substância" quando o "eu" for pensado como sujeito de todos os possíveis predicados. ${ }^{42}$ E este "eu" será legitimado como sujeito de todos os "A kzidentien" e predicados possíveis, a base de constituição dos objetos e como tal apenas, isto é, como sujeito e não como o próprio predicado de algo ${ }^{43}$ Kant entende essa substância como única, inteligível, espontânea ${ }^{44}$ e sem objeto do fenômeno (Refl. 5460, XVIII, 189).

Sabemos também que Kant entende essa existência como não-temporal: "Os paralogismos começam na existência como modalidade: 'eu sou'; vão para a relação para não definir a existência no tempo, o qual seria empírico. Portanto: eu sou como substância da qualidade..." (Refl. CLVI, XXIII, 38-9). Precisamente esta característica básica da existência, isto é, o fato de ela não ser temporal significa também que ela não pode vir à consciência sob as condições de limitação da espontaneidade por meio do dado receptivo. Com isso, a existência dissociada das categorias não diz respeito a um sujeito pensante empírico, pois, por não estar no tempo e no espaço, não pode ser definida na forma sintética, sendo, portanto, uma existência indefinida. Sendo assim, as considerações de Kant não estão de acordo com teses como a de Aquila (1979, p.263),

40 Kant define a alma (Seele) como substância afirmando que ela "existe" como "substância" (XXIII, 50), mas, neste caso, não entendendo a substância como categoria empírica, como ocorre no quarto paralogismo, em B 410-1 e B 422.

41 "Ora, a simples apercepção (o eu) é substância no conceito, é simples no conceito etc., e assim todos esses teoremas psicológicos possuem a sua exatidão incontestável. Contudo, desse modo, não se conhece aquilo que propriamente se desejava saber acerca da alma ..." (A 400).

42 Na M etaphysik-Pölitz se procura responder por que o "eu-sujeito" pode ser denominado uma substância: “... [1] Substância é o primeiro sujeito de todos os acidentes inerentes. [2] Mas este eu é um sujeito absoluto, ao qual todos os acidentes e predicados podem ocorrer, e o que realmente não pode ser predicado de uma outra coisa. [3] Portanto, o eu expressa o substancial ..." (XXVIII, 225-6).

43 "De cada coisa em geral posso dizer que é substância, conquanto que a distinga de simples predicados e de simples determinações das coisas ... Portanto, cada um deve considerar-se a si mesmo, necessariamente, como uma substância e os seus pensamentos, porém, apenas como acidentes da sua existência e determinações do seu estado" (A 349).

44 XXVIII, 265-7. Comparar com as reflexões: 5451-5452, 5454, 5458, 5462 e 5481 em XVIII, 186, 188,189 e 195. 
segundo a qual a consciência da própria existência compreende necessariamente o múltiplo (Mannigfaltiges) empírico ou a de Todes (1968), para o qual o saber da realidade (Wirklichkeit) de si próprio é um saber de um eu empírico e não o saber de um sujeito pensante. ${ }^{45}$

Por outro lado, se não podemos entender a existência neutra ou nãocategorial como empírica, o saber sobre ela também não permite associála à intuição intelectual, pois isso não é possível ser pensado com relação à própria autoconsciência, ou seja, não é correto pensar que esta existência ou a autoconsciência têm por base uma intuição intelectual. Quando Kant afirma que o "eu penso" é uma representação pura e intelectual, ${ }^{46}$ ou indica que somos conscientes de nós no simples ato "eu penso" como uma espontaneidade que faz com que nos denominemos inteligência (B 158 n.), isso quer dizer apenas que o "eu sou" e, por decorrência, a existência não-categorial pertencem ao pensamento em geral, não estando portanto no nível da intuição (B 157). ${ }^{47}$

Com isso, não é possível interpretar que a existência do sujeito, pensada neutra na autoconsciência só é compreensível sob a concepção de uma intuição intelectual, como crê Frank. ${ }^{48}$ É preciso confrontar as passagens B 139-40; B 158, B 278 - em que Kant faz uso de termos como "intuição" e "representação" intelectual e afirma que existimos como "inteligência" -, e a reflexão: "Eu penso é um princípio a priori, é uma simples categoria do sujeito, representação intelectual sem qualquer lu-

45 Contra essa tese, ver Lütterfelds, 1975, p.19.

46 “....a consciência de mim próprio na representação eu não é uma intuição, mas uma representação simplesmente intelectual da espontaneidade de um sujeito pensante" (B 278);

- “...se eu denominei o princípio eu penso um princípio empírico, eu não quero dizer por meio disso que o eu neste princípio seja uma representação empírica; pelo contrário, ela é uma [representação, C. M.] pura intelectual, porque ela pertence ao pensar em geral" (B 423 n.).

47 E é preciso considerar a diferença que Kant estabelece entre pensamento e intuição: "O pensamento, considerado em si, é simplesmente a função lógica, por conseguinte, a simples espontaneidade da ligação do múltiplo de uma intuição apenas possível, e não representa o sujeito da consciência como fenômeno, porque não considera a espécie de intuição, isto é, se esta é sensível ou intelectual" (B 428-9).

48 'Trata-se de uma intuição no eu puro, pois ela - como 'receptividade' na diferença da 'espontaneidade' da inteligência - poderia provar a existência (posição absoluta); a intuição, não obstante, é intelectual, porque ela está na espontaneidade pura do entendimento e leva consigo a idéia de uma 'certeza' perfeita." (Frank, 1993, p.425). Frank fala também sobre um "ser supra-sensível" ("übersinnliche(s) Seiende(s)"): “... no qual seria nos suposto a nota na p.422-3 da edição B da KrV: a existência de um ser pré-categorial e supra-sensível está para esclarecer, a qual atua igualmente como princípio deste, o que tem no eu o caráter de um fenômeno e o conhecimento é acessivel (cf. KpV 9-10). Agora, apenas uma intuição intelectual pode ter acesso a uma tal 'realidade suprasensível' que indubitavelmente mantém-se no lado de cá do limite, no outro lado do qual a esfera do cognoscível começa" (p.430). 
gar e qualquer tempo, portanto, não empírica. Se nisso está a categoria de realidade, se disso são indicados os fins objetivos..." (CLX, XXIII, 39) com as seguintes passagens:

Se à consciência intelectual da minha existência na representação "eu sou", que acompanha todos os meus juízos e atos do entendimento, pudesse juntar, ao mesmo tempo, uma determinação da minha existência pela intuição intelectual, então a consciência de uma relação a algo existente fora de mim não pertenceria necessariamente a esta determinação. ( $B \mathrm{XL}$.)

A consciência de si mesmo (a apercepção) é a representação simples do eu e se, por ela só, nos fosse dada, espontaneamente, todo o múltiplo que se encontra no sujeito, a intuição interna seria então intelectual." (B 68)

eu existo como inteligência simplesmente consciente da sua faculdade de síntese... essa inteligência só pode conhecer-se tal como aparece a si mesma com respeito a uma intuição (que não pode ser intelectual nem ser dada pelo próprio entendimento) e não como se conheceria se a sua intuição fosse intelectual. (B 158-9)

Então, a partir desse confronto, pode-se considerar que Kant dá um sentido figurado àqueles termos, para com isso evidenciar o contraste dessa concepção de existência perante a intuição sensível e não para fundamentá-la na intuição intelectual.

Como não cabe à existência neutra uma intuição sensível, porque ela não é pensada com referência à aplicação das categorias, fica por fim a possibilidade de pensá-la com relação à intuição não-sensível, ${ }^{49}$ já que nesta não se encontra a grandeza extensiva (relativa ao tempo e ao espaço). Nessa intuição, que não pode ser suposta como "supra-sensível", 50 as formas puras da sensibilidade não se incluem e no múltiplo dela é dado apenas um entendimento discursivo (B 130, B 148-9); nela, o conceito de ligação (que está no objeto) é produzido pelo próprio sujeito dessa forma, é pensada a "espontaneidade da ligação do múltiplo de uma simples intuição possível ... (B 278). Esta intuição não-sensível está ligada à sensação, daí Kant considerar que o pensamento está conectado a um "sentimento de existência" ("Gefühl des Daseins" - IV, 334 n.).

Frank, com razão, constata que essa existência da autoconsciência "é um ser sem toda característica e qualidade ... dele eu sei apenas 'que

49 Ver B 130, B 148-9, B 159.

50 Como faz Baum (1986, p. 84) que, com base no Preisschrift über die Fortschritte der Metaphysik (XX, 272), sugere que uma intuição não sensível ("unsinnlich") seja o mesmo que intuição suprasensível ("übersinnliche"). E isto não é possível porque Kant se refere ao supra-sensível apenas em seus escritos de filosofia prática. 
ele é'; nunca: 'o que ele é' ou 'como ele se aparece'..." (1993, p.419-20), todavia, não é possível entender, como ele o faz, que esse saber tão limitado se constitua em algo "desastroso" para a filosofia teórica. ${ }^{51}$ Ao contrário, se procuramos pela fonte deste saber vemos que, precisamente em nossa faculdade perceptiva, podemos encontrar a importância da filosofia teórica para a prática, pois nela se constitui um saber que aponta os limites do conhecimento sensível e é com ela que a autoconsciência obtém o status de um "ser objetivo" (objektive Sein), sem o qual não haveria filosofia prática alguma, pois que, todavia, esta não tem condições de fornecê-lo a nós. Os limites das especulações analíticas não reduzem a filosofia teórica a nada e nem sequer constituem um desastre; apenas apontam para o papel fundamental dela junto à filosofia prática na compreensão de nossa natureza.

Com isso, cabe agora pensar, em relação à autoconsciência e à existência nela contida, as questões relativas ao próprio saber que temos delas. De onde provém este saber? Por meio do que ele é obtido?

Embora esse saber não seja do âmbito racional-empírico, ele é adquirido por meio da percepção, só por meio dela é possível saber da existência ("... que minha própria existência possa ser apenas o objeto de uma simples percepção." - A 367-8). E só a respeito da existência é possível ter uma percepção direta (A 367). Mas a percepção não éa apercepção transcendental; segundo o nosso entender, embora nem sempre esteja claro, Kant trabalha com dois conceitos não similares, ${ }^{52}$ sendo a percepção apenas a determinação da apercepção (A 368). A percepção repousa sobre um ato da apercepção transcendental; ${ }^{53}$ nela, percepção indefinida, o sujeito é consciente de seu próprio saber.

51 "Em outras palavras: neste ponto o conhecimento sozinho fornece a mim saber objetivo, não pode existir conhecimento do (puro) eu. Mas dificilmente é reconhecido este raciocínio, compreende-se que ele tem conseqüências desastrosas para a compreensão daquele ponto supremo da filosofia teórica" (Ibidem, p.419).

52 A fonte que serviu para Kant diferenciar percepção de apercepção parece estar em Leibniz: "Ainsi il est bon de faire distintion entre la perception qui est l' état intérieur de la monade representant les choses externes, et l'aperception qui est la conscience, ou la connaissance réflexive de cet état intérieur, laquelle n'est point donnée a toutes les âmes, ni toujours à la même âme" (Leibniz, 1965, v.4, p.600). Cabe observar que aqui não deduzimos uma relação entre a apercepção transcendental de Kant e o "eu" de Leibniz, pois, como mostra Brandt (1994, p.3-4), a mesma não é possível. Com a observação acima apenas sugerimos que os termos kantianos em foco parecem se originar do vocabulário leibniziano.

53 "Isso, o que deve ser necessariamente representado como numericamente idêntico, não pode ser pensado, como tal, por meio de dados empíricos. Deve haver uma condição, que preceda toda a experiência e torne esta mesma possível, a qual deve tornar válida um tal pressuposto transcendental" (A 107). 
Tanto a percepção indefinida quanto o fato de ela ser direta estão supostos na autoconsciência. $E$ isso Frank, na sua interpretação, parece ignorar. Considerando a fala de Kant em A 345-6/, B 40454 e em A 365-3,55 Frank observa: "O ser pré-predicativo da pura apercepção fica portanto no escuro; ou mais corretamente (porque nós não podemos renunciar a ele): de resto não nos fica nada que supô-lo sempre" (1993, p.426). Primeiramente parece evidente que essa interpretação está embasada no descuido com a diferença existente entre os conceitos contidos nas passagens em relação às quais 0 autor a tece. A pura apercepção, assim entendemos, não deve ser confundida com a percepção indefinida - 0 "Sein" é apreendido por esta (A 368), a qual está na autoconsciência, que por sua vez contém a existência.

Por outro lado, as próprias palavras de Kant não se harmonizam com a interpretação de Frank, quando esta nega que a percepção seja direta: "Além disso, Kant negou ... obstinadamente a possibilidade de um euapercepção direto" (Ibidem). Uma análise mais profunda do parágrafo completo A 365-6 revela que Kant refere-se aí a dois processos:

- o conhecimento de nós mesmos como objeto transcendental, o qual é impossível;

- a autoconsciência não tem outro termo de comparação "a não ser eu próprio com as condições gerais da minha consciência.." - aqui precisa ser constatada a fala do autoconhecimento vinculada à autoconsciência: só tenho um termo de comparação, este termo sou eu próprio e isso me possibilita um autoconhecimento (ainda que parcial, mas não indireto) pois eu substituo "meu conceito e a sua unidade pelas qualidades que convêm a mim próprio como objeto e pressuponho aquilo que se desejava saber".

54 Onde o eu transcendental é definido como "a representação eu, representação simples e, por si só, totalmente vazia de conteúdo ... que apenas se conhece pelos pensamentos, que são seus predicados e do qual não podemos ter, isoladamente o menor conceito; movemo-nos aqui, portanto, num círculo perpétuo, visto que sempre necessitamos previamente, da representação do eu para julgar qualquer coisa dele" (A 345-6/, B 404).

55 “...pois esse conceito [eu idêntico, C. M.] gira sempre sobre si mesmo e não nos faz avançar um só passo relativamente àquelas questões que dizem respeito ao conhecimento sintético. Que espécie de coisa em si mesma (objeto transcendental) seja a matéria é-nos, sem dúvida, completamente desconhecido; não obstante, pode a sua permanência ser observada como fenômeno, visto que é representada como algo exterior. Mas como, quando quero observar o simples eu na mudança de todas as representações, não tenho outro termo de comparação a não ser eu próprio com as condições gerais da minha consciência, no sentido em que substituo o meu conceito e a sua unidade pelas qualidades que convêm a mim próprio como objeto, e pressuponho aquilo que se desejava saber" (A 365-6). 
$\mathrm{Na}$ autoconsciência, a percepção de si próprio é sim direta, pois é o próprio "eu" que substitui o "seu" conceito pelas qualidades que a "ele" convém (e se isso corresponde ao que ele é verdadeiramente, é uma outra questão); também há uma relação direta do eu consigo próprio quando ele vai pressupor aquilo que desejava saber. Não se trata assim de afirmar que o ser da pura apercepção é "obscuro" e que a autopercepção é "indireta", mas sim de separar claramente autoconhecimento de autoconsciência. $\mathrm{Na}$ autoconsciência em geral, eu tenho uma consciência direta de minha própria existência, essa consciência constitui um saber, mas não significa que eu me conheça como objeto.

Com relação à percepção indefinida, o que se coloca como problemático não é propriamente o fato de ela ser direta, mas sim o fato do "eu penso" ser esta percepção ao mesmo tempo que Kant o define como percepção empírica. Como se esclarece tal (aparente) contradição? Veremos que, mesmo nesse caso, nada está "no escuro", pois esta percepção diz respeito à existência não-categorial.

0 "eu penso" é uma percepção indefinida (unbestimmte Wahrnehmung) e, como tal, ele também é uma percepção não-empírica, assim esta percepção indefinida que ele expressa "significa aqui apenas algo real, que é dado realmente apenas ao pensar em geral, portanto, não como fenômeno, também não como coisa em si mesma (Noumenon) mas como algo, que de fato existe e será indicado como tal no princípio eu penso" (B 423 n.). Se não é empírico e tampouco Noumenon, como entender o "eu penso" como percepção indefinida relacionado à expressão "o que de fato existe" ("was in der Tat existiert")? A que se refere tal existência?

A expressão "was in der Tat existiert" significa aqui, como disse Kant, só o "algo real" ("etwas Reales"), pois no ato "eu penso" existe consciência de si próprio se for dado ao pensar "etwas Reales", e este "real" significa um real indefinido, isto é, não é um real materializável, não é fenomenal e nem metafísico, pois refere-se ao indefinido pensar em geral. Isso se evidencia melhor quando, na mesma nota, Kant escreve sobre o princípio empírico "eu penso" não o tratando como objeto do conhecimento (pois ele aí não é empírico porque se refere à determinação empírica da existência), mas sim entendendo-o como "uma intuição indeterminada, isto é, percepção" e, como tal, prova "que já a sensação pertencente à sensibilidade serve de fundamento a esta proposição de existência..." (B 422-3n.). Ora, a sensação (Empfindung) aqui, como base do princípio existencial "eu penso", e por conseguinte da própria percepção indefinida, responde à incógnita a respeito desta concepção de "real", isto é, "o que de fato existe" significa que a simples existência contida no 
"eu penso" não se refere a intuições espaciais e sim a uma grandeza intensiva. É isso o que Kant coloca em B 208 sobre a sensação: "Porque a sensação não é, em si mesma, uma representação objetiva e nela não se encontra nem a intuição do espaço, nem a do tempo, não Ihe competirá uma grandeza extensiva, mas terá contudo uma grandeza ... terá pois uma grandeza intensiva, em correspondência com a qual se deverá atribuir a todos os objetos da percepção, na medida em que esta contém sensação, uma grandeza intensiva, isto é, um grau de influência sobre os sentidos". 0 "etwas Reales" verdadeiramente existe, mas o seu modo de existência na autoconsciência é indefinido - porque nela nada pode ser definido, nada pode ser suficientemente conceituado. Portanto, não deixa de ser legítimo afirmar que esta autoconsciência é "definida" por meio da "percepção empírica indefinida 'eu penso'", e não por meio de uma "percepção empírica" definida.

Mas com isso ainda não fica claro no que consiste este "etwas Reales", isto é, no que consiste este "eu" que se percebe e como este se perceber se constitui. Não se trata de um "eu" empírico nem de um sujeito transcendental, pois este "eu" é apenas um objeto, ${ }^{56}$ por meio do qual Kant entende que o sujeito se desdobra e mantém com isso uma relação próxima, íntima ${ }^{57}$ consigo mesmo, a qual se constitui em uma auto-observação: "A consciência do observante de si próprio é uma representação totalmente simples do sujeito no juízo em geral de que tudo se sabe, quando simplesmente se a pensa... mas o eu observado por si mesmo é uma essência de muitos objetos da percepção interna que a psicologia completamente tem a fazer para dizer tudo que nisso está em segredo e não deve jamais esperar com isso chegar ao fim e responder suficientemente à questão: o que é o homem" (W, XII, 428). Esta observação de si não é algo comum, ${ }^{58}$ ao contrário, "A auto-observação é difícil e antinatural..." (XXV, 31-2), nela 0 afeto não deverá constar, ${ }^{59}$ pois não se trata de uma observação das próprias sensações (Empfindungen), mas de uma auto-observação que ocorre no nível da filosofia analítica e constitui sua parte mais exaustiva. ${ }^{60}$

56 "O eu contrário do sentido interno, isto é, da percepção e observação de si mesmo, não é o sujeito do juízo, mas um objeto" (W, XII, 428).

57 Henrich $(1973$, p.86 e 1989, p.91) e Frank $(1993$, p.432) denominam tal relação de "intimidade" do sujeito consigo próprio.

58 "O costume de observar a si próprio é prejudicial..." (XXV, 31-2).

59 "Se está em afeto, então não se observa; pois segundo o afeto não se pode observar" (XXV, 3).

60 "A parte analítica da filosofia, em que se analisam seus conceitos e também se observa a si próprio, é a parte mais cansativa da filosofia" (XXV, 32-3). 
J ustamente quando o sujeito se faz como algo a ser dado para a autopercepção, quando ocorre esse "desdobrar-se" em objeto, é que a consciência se diferencia do fenômeno (aparência) e da coisa em si (Noumeno): na simples consciência existe a autoconsciência se algo real Ihe for dado, algo que não pode ser considerado como fenomênico ou noumenal, mas apenas como indefinido. É possível que o "eu" se perceba como simples espontaneidade porque é possível o "tornar-se" consciente das simples funções lógicas do pensar, sem que com isso seja pensada alguma unidade sintética das representações. Com isso, o "eu" referese às funções lógicas em geral e a algo. Este algo nada mais é que 0 próprio "eu".

MARTINS, C. A. Pure self-conscience, identity and existence in Kant. Trans/ Form/Ação (São Paulo), v.21-22, p.67-89, 1998-1999.

- ABSTRACT: This article identifies the relation between the transcendental apperception and identity, existence and perception, and on this basis tries to demonstrate that self-conscience - though a fundamental element in the structure of human cognition - doesn't ground knowledge.

- KEYWORDS: Pure self-conscience; cognitive structure; identity; perception.

\section{Referências bibliográficas}

AQUILA, R. E. Personal identity and Kant's "Refutation of idealismus". KantStudien, v.70, p.259-78, 1979.

BAUM, M. Deduktion und Beweis in Kants Transzendentalphilosophie. Untersuchungen zur Kritik der reinen Vernunft. Hain bei Athenäum: Königstein/Ts, 1986.

BECKER, W. Selbstbewußtsein und Erfahrung. Zu Kants transzendentaler Deduktion und ihrer argumentativen Rekonstruktion. Freiburg: Karl Alber, 1994.

BENNETT, J . Kant's A nalytic. Cambridge: Cambridge University Press, 1966.

BRANDT, R. (Org.) Über das Bewußtsein. (Pseudo-Mayne, 1728). Hamburg: Felix Meiner, 1983. 
Historisches zum Selbstbewußtsein. In: TUSCHLING, B. (Org.) Probleme der "Kritik der reinen Vernunft" - Kant Tatung Marburg 1981. Berlin: W. de Gruyter, 1984.

. Rousseau und Kants "Ich denke". In: BRA NDT, R., STARK, W. (Org.) Autographen, Dokumente und Berichte. Hamburg: Editora Felix M einer, 1994 p.1-18.

FRANK, M . Fragmente einer Geschichte der Selbstbewußtseins-Theorie von Kant bis Sartre. In: . (Org.) Selbstbewußtseinstheorie von Fichte bis Sartre. 2.ed. Frankfurt/M ain: Suhrkamp, 1993. p.413-99.

GUYER, P. Kant and the Claims of Knowledge. Cambridge: Cambridge University Press, 1987.

HENRICH, D. Der Begriff der sittlichen Einsicht und Kants Lehre vom Faktum der Vernunft. In: PRAUSS, G. (Org.) Kant - Zur Deutung seiner Theorie von Erkennen und Handeln. Köln: Gütersloh, Kiepenheuer \& Witsch, 1973.

. Ding an sich: ein prolegomenon zur metaphysik des endlichen. In: ROHLS, J., WENZ, G. (Org.) Vernunft des Glaubens. Wissenschaftliche Theologie und kirchliche Lehre. Göttingen: s. n. 1989. p.42-92.

HINSCH, W. Erfahrung und Selbstbewußtsein. Hamburg: Meiner, 1986.

KANT, E. Gesammelte Schriften. Berlim: Preussischen und Deutschen A kademie der Wissenschaften, 1902.

LEIBNIZ, G. W. Principes de la nature et de la gracê fondés en raison. In: GERHARDT, C. I. (Org.) Die Philosophischen Schriften. Berlin (1875-1890)Hildesheim, 1965. v.4

LÜTTERFELDS, W. Zum undialektischen Begriff des Selbstbewußtseins bei Kant und Fichte. Wiener J ahrbuch für Philosophie (Wien), v.8, p.7-38, 1975.

MOHR, G. Das sinnliche Ich. Innerer Sinn und Bewußtsein bei Kant. Würzburg: Königshausen und Neumann, 1991.

STRAWSON, P. F. Kant's paralogisms: self-consciousness and the "outside observer". In: CRAM ER, K. et al. (Org.) Theorie der Subjektivität. Frankfurt: Suhrkamp, 1987.

STURM A, D. Kant über Selbstbew ußtsein: Zum Zusammenhang von Erkentniskritik und Theorie des Selbstbewußtseins. Hildesheim: Georg Olms, 1985.

TODES, S. J. Knowledge and the ego: Kant's three stages of self-evidence. In: WOLFF, R. P. (Org.) Kant a Collection of Critical Essays. Indiana: Notre Dame, 1968. p.156-71. 